\title{
Li3Mo4P5O24: a Two-Electron Cathode for Lithium-Ion Batteries with Three-Dimensional Diffusion Pathways
}

\author{
B. Wen \\ Submitted to Chemistry of Materials
}

April 2016

Chemistry Department

Brookhaven National Laboratory

\author{
U.S. Department of Energy \\ [DOE Office of Science]
}

\begin{abstract}
Notice: This manuscript has been authored by employees of Brookhaven Science Associates, LLC under Contract No. DE- SC0012704 with the U.S. Department of Energy. The publisher by accepting the manuscript for publication acknowledges that the United States Government retains a non-exclusive, paid-up, irrevocable, world-wide license to publish or reproduce the published form of this manuscript, or allow others to do so, for United States Government purposes.
\end{abstract}




\section{DISCLAIMER}

This report was prepared as an account of work sponsored by an agency of the United States Government. Neither the United States Government nor any agency thereof, nor any of their employees, nor any of their contractors, subcontractors, or their employees, makes any warranty, express or implied, or assumes any legal liability or responsibility for the accuracy, completeness, or any third party's use or the results of such use of any information, apparatus, product, or process disclosed, or represents that its use would not infringe privately owned rights. Reference herein to any specific commercial product, process, or service by trade name, trademark, manufacturer, or otherwise, does not necessarily constitute or imply its endorsement, recommendation, or favoring by the United States Government or any agency thereof or its contractors or subcontractors. The views and opinions of authors expressed herein do not necessarily state or reflect those of the United States Government or any agency thereof. 


\section{$\mathrm{Li}_{3} \mathrm{Mo}_{4} \mathrm{P}_{5} \mathrm{O}_{24}$ : a Two-Electron Cathode for Lithium-Ion Batteries with Three-Dimensional Diffusion Pathways}

Bohua Wen, Jue Liư ${ }^{2,3}$, Natasha A. Chernova, Xiaoya Wang, Yuri Janssen², Fredrick Omenya, Peter G. Khalifah ${ }^{2,3}$, and M. Stanley. Whittingham

${ }^{1}$ Chemistry and Materials Science and Engineering, State University of New York at Binghamton, Binghamton, New York 13902-6000, United States

${ }^{2}$ Department of Chemistry, State University of New York at Stony Brook, Stony Brook, New York 11794-3400, United States

${ }^{3}$ Department of Chemistry, Brookhaven National Laboratory, Upton, New York, 11973-5000

Keywords: Li-ion batteries, cathodes, molybdenum(5+), phosphates, two-electron transfer.

Abstract: The structure of the novel compound $\mathrm{Li}_{3} \mathrm{Mo}_{4} \mathrm{P}_{5} \mathrm{O}_{24}$ has been solved from single crystal X-ray diffraction data. The Mo cations in $\mathrm{Li}_{3} \mathrm{Mo}_{4} \mathrm{P}_{5} \mathrm{O}_{24}$ are present in four distinct types of $\mathrm{MoO}_{6}$ octahedra, each of which has one open vertex at the corner participating in a $\mathrm{Mo}=\mathrm{O}$ double bond and whose other five corners are shared with $\mathrm{PO}_{4}$ tetrahedra. Based on a bond valence sum difference map (BVS-DM) analysis, this framework is predicted to support the facile diffusion of $\mathrm{Li}^{+}$ions, a hypothesis which is confirmed by electrochemical testing data which shows that $\mathrm{Li}_{3} \mathrm{Mo}_{4} \mathrm{P}_{5} \mathrm{O}_{24}$ can be utilized as a rechargeable battery cathode material. It is found that Li can both be removed from and inserted into $\mathrm{Li}_{3} \mathrm{Mo}_{4} \mathrm{P}_{5} \mathrm{O}_{24}$. The involvement of multiple redox processes occurring at the same Mo site is reflected in electrochemical plateaus around 3.8 V associated with the $\mathrm{Mo}^{6+} / \mathrm{Mo}^{5+}$ redox couple and $2.2 \mathrm{~V}$ associated with the $\mathrm{Mo}^{5+} / \mathrm{Mo}^{4+}$ redox couple. The two-electron redox properties of Mo cations in this structure lead to a theoretical capacity of 198 
$\mathrm{mAh} / \mathrm{g}$. When cycled between 2.0 and $4.3 \mathrm{~V}$ vs. $\mathrm{Li}^{+} / \mathrm{Li}$, an initial capacity of $113 \mathrm{mAh} / \mathrm{g}$ is observed with $80 \%$ of this capacity retained over the first 20 cycles. This compound therefore represents a rare example of a solid state cathode able to support 2-electron redox capacity, and provides important general insights about pathways for designing next-generation cathodes with enhanced specific capacities.

\section{Introduction:}

Transition metal oxides - such as $\mathrm{LiCoO}_{2}$ with the layered $\alpha-\mathrm{NaFeO}_{2}$ structure type were the first generation of commercialized cathodes in lithium-ion batteries (LIBs) ${ }^{1}$. Later, discovery of olivine-structured lithium iron phosphate $\left(\mathrm{LiFePO}_{4}\right)$ with enhanced safety and high rate capability led to extensive studies focused on polyanionic compounds and phosphates ${ }^{2,3}$. However, these compounds have much lower volumetric energy density than analogous oxides. One way to increase the energy density is to utilize more than one-electron transfer per redox center. Many attempts have been made towards this goal ${ }^{4,5}$, and a very good example is the $\mathrm{VOPO}_{4} / \mathrm{LiVOPO}_{4}$ system $^{3,6-8}$. However, this vanadyl phosphates system cannot reversibly cycle two lithium ions per formula unit. Molybdenum is another well-known element with multiple redox couples, but has rarely been studied for LIBs because of the large atomic mass of Mo. However, recent calculations from G. Hautier et al., show the strong possibility of multiple close redox potentials for Mo within an acceptable voltage range for Li-ion batteries ${ }^{9}$. Our previous study of the layered molybdenum (oxy)pyrophosphate indicated that this compound has a slightly lower voltage plateau than was calculated by DFT, and that the second lithium (per molybdenum) cannot be reversibly intercalated in the structure in experiments, in contrast to the DFT predictions ${ }^{10}$. This exemplifies the 
significant challenges in finding good structures for accommodating multiple electron transfer during electrochemical cycling. Molybdenum is most stable in the 6+ oxidation states under common reactions under ambient atmosphere, so only a small number of reduced (5+ or $4+$ ) molybdenum phosphates are described in structural databases.

In this work, we have synthesized a novel (oxy)phosphate compound $\mathrm{Li}_{3} \mathrm{Mo}_{4} \mathrm{P}_{5} \mathrm{O}_{24}$ with pentavalent Mo cations and a theoretical capacity of $198 \mathrm{mAh} / \mathrm{g}\left(7 \mathrm{Li}^{+} /\right.$per formula unit), and have determined the structure of this phase using single crystal X-ray diffraction methods. During electrochemical testing, this compound was found to exhibit two reversible plateaus at $\sim 3.8 \mathrm{~V}$ and $2.2 \mathrm{~V}$, corresponding to the $\mathrm{Mo}^{6+} / \mathrm{Mo}^{5+}$ and $\mathrm{Mo}^{5+} / \mathrm{Mo}^{4+}$ redox couples, leading to have an accessible capacity of $\sim 100 \mathrm{mAh} / \mathrm{g}$ at a C/50 rate. This compound could be reversibly cycled for 20 cycles without structural decomposition, a rate example of a solid state system which can reversibly access multiple oxidation states and thus provides important insights into methods for designing the next generation of high capacity cathode materials that are required for advanced battery applications.

\section{Experimental Details}

Synthesis $\mathrm{Li}_{3} \mathrm{Mo}_{4} \mathrm{P}_{5} \mathrm{O}_{24}$ was synthesized from $\mathrm{MoO}_{3}$ (Alfa Aesar), $\mathrm{NH}_{4} \mathrm{H}_{2} \mathrm{PO}_{4}$ (Sigma Aldrich, $\geq$ $99.99 \%$ ), $\mathrm{Li}_{2} \mathrm{CO}_{3}$ (Fisher Scientific, $\geq 99 \%$ ), and oxalic acid (Aldrich, $99 \%$ ). First, $\mathrm{MoO}_{3}$ and oxalic acid, in a 1:3 molar ratio, were dissolved in deionized water at $75{ }^{\circ} \mathrm{C}$ with stirring to form a blue solution. Here, oxalic acid serves both as a chelating reagent and a reducing agent. Next, $\mathrm{NH}_{4} \mathrm{H}_{2} \mathrm{PO}_{4}$ and $\mathrm{Li}_{2} \mathrm{CO}_{3}$, in a 1:1 molar ratio, were added into the solution, stirred for $4 \mathrm{~h}$, and then heated at $100{ }^{\circ} \mathrm{C}$ in air within an oven. The overall molar ratio of the solution was 2:1:2 Li:Mo:P. 
The resulting gel was decomposed at $350{ }^{\circ} \mathrm{C}$ for $6 \mathrm{~h}$, ground and finally pressed into pellets. The pellets were pre-heated at $650^{\circ} \mathrm{C}$ for $2 \mathrm{~h}$, and then heated to $750{ }^{\circ} \mathrm{C}$ for another $2 \mathrm{~h}$ of reaction. The resulting melt was initially slow-cooled at a rate of $5^{\circ} \mathrm{C} / \mathrm{h}$ to $550{ }^{\circ} \mathrm{C}$, and then cooled naturally in the furnace to the room temperature. All heating and cooling was conducted in an alumina crucible and under flowing argon gas (30 mL/min). The cooled melt was crushed into large chunks, from which small single crystals were isolated for single-crystal diffraction studies. Dark green powders were obtained after grinding the product melt, which were used for the powder diffraction studies and electrochemical testing. Morphology and particle size were studied by a field-emission scanning electron microscope (Supra 55 VP, Zeiss), the images are presented in Figure S1.

Single Crystal Diffraction Single crystal X-ray diffraction data for $\mathrm{Li}_{3} \mathrm{Mo}_{4} \mathrm{P}_{5} \mathrm{O}_{24}$ were collected at room temperature with an Oxford Diffraction Gemini Atlas diffractometer using Mo $\mathrm{K}_{\alpha}$ radiation. The majority phase (blue crystals) was found to also be accompanied by crystals of two distinct minor phases which were white and green in color, and thus could be easily identified. A $0.2 \times 0.1$ $\times 0.1 \mathrm{~mm}$ blue crystal of $\mathrm{Li}_{3} \mathrm{Mo}_{4} \mathrm{P}_{5} \mathrm{O}_{24}$ was picked for single crystal diffraction study, and data were collected over an angular range of $3.3^{\circ}$ to $33.0^{\circ}$ in $\theta$, corresponding to a $d_{\min }$ of $0.65 \AA$. Data reduction and an analytical face-indexed absorption correction (using the measured crystal shape) were performed using CrysAlisPro (v. 171.35.19). The as-collected data were further analyzed using the WinGX software front end ${ }^{11}$, starting with space group determination and then structure solution through direct methods (which identified the Mo, P and $\mathrm{O}$ atomic sites) using both the Sir2004 $4^{12}$ and Superflip ${ }^{13}$ software packages. Preliminary structural refinement was carried out using both Jana2006 ${ }^{14}$ and Shelx $197^{15}$, with the latter used for the final structure refinement. Even 
after all of the atomic sites were identified and included in the refinement, the value of the refinement $R_{1}$ was substantially higher than $R_{\text {int }}$ for the diffraction data - a potential warning sign

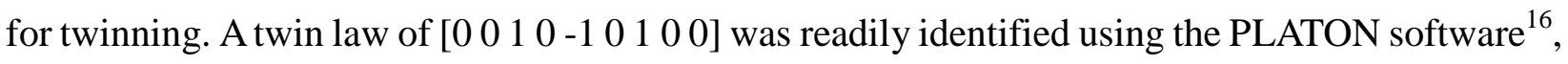
whose inclusion in the refinement substantially improved the quality of the fit and allowed the previously unresolvable Li sites to be identified.

Bond Valence Sum Maps Bond valence sum difference maps (BVS-DMs) were calculated by method and software previously developed to study $\mathrm{Na}_{3} \mathrm{TiP}_{3} \mathrm{O}_{9} \mathrm{~N}^{17}$. The absolute value of the difference $(|\Delta \mathrm{V}|)$ between the calculated valence of $\mathrm{Li}$ at each point on a 3D grid $(100 \times 100 \times 100)$ within the unit cell and the ideal valence of 1 was then plotted as an isosurface in VESTA ${ }^{18}$, allowing likely diffusion pathways to be graphically identified. The threshold for Li-ion diffusion was then estimated by identifying the minimal $|\Delta \mathrm{V}|$ threshold needed to produce a percolating pathway between the cation sites. For this system, the minimal $|\Delta V|$ was estimated to be $\sim 0.03$, indicating relative low energy barrier for lithium diffusion. The diffusion pathway is found to be fully 3D, connecting both Li2 and Li3 sites, while Li1 site is found to be isolated from the potential diffusion pathways.

Powder Diffraction High resolution synchrotron powder diffraction data were collected at $298 \mathrm{~K}$ with an average wavelength of $0.413670 \AA$ Asing beamline 11-BM of the Advanced Photon Source (APS) at Argonne National Laboratory. Data points were collected with a step size of $0.001^{\circ}(2 \theta)$ and a scan speed of $0.01 \%$ across the 13 different diffracted beam monchromators ${ }^{19}$. Rietveld refinement of the powder diffraction data was carried out in TOPAS software (version 4.2), and a fundamental parameters approach was used to model the diffraction peak shapes. When the 
structure model solved from single crystal diffraction data was used to model the as-collected powder diffraction pattern, the positions and intensities of the majority of the experimentally observed diffraction peaks were effectively modeled. However, at least two types of minor phases were seen in diffraction patterns, presumably corresponding to the green and white single crystals. One minority phase (dark grey) was identified to be $\mathrm{MoO}_{2}$, while the other phase could not be readily identified.

Electrochemical testing Melt products (containing the main phase of $\mathrm{Li}_{3} \mathrm{Mo}_{4} \mathrm{P}_{5} \mathrm{O}_{24}$ ) and carbon black were mixed in a weight ratio of 70:20 and ball milled for 30 min to reduce the particle size (Figure S1). Then 10 wt.\% of polyvinylidene fluoride (PVDF) was added using 1-methyl-2-pyrrolidinone (NMP) as a solvent to form a slurry. The slurry was then cast onto an $\mathrm{Al}$ foil current collector and dried in air at $80^{\circ} \mathrm{C}$ for $6 \mathrm{~h}$. The dried electrodes (with an area of $1.2 \mathrm{~cm}^{2}$ and containing $\sim 3 \mathrm{mg}$ of active material) were loaded into 2325-type coin cells within a He-filled glovebox together with pure lithium foil (Aldrich, thickness $0.38 \mathrm{~mm}$ ) which was used as the counter and reference electrodes in a half-cell, with the two electrodes separated by a Celgard 2400 separator (Hoechst Celanese). $1 \mathrm{M} \mathrm{LiPF}_{6}$ in a 1:1 volume ratio of ethylene carbonate (EC) and dimethyl carbonate (DMC) was used as electrolyte. The electrochemical properties of $\mathrm{Li}_{3} \mathrm{Mo}_{4} \mathrm{P}_{5} \mathrm{O}_{24}$ were evaluated using a VMP multichannel potentiostat (Bio-Logic). Cyclic voltammetry (CV) testing was done at a slow scan rate of $0.005 \mathrm{mV} / \mathrm{s}$ while the galvanostatic charge and discharge experiments were performed at current densities of $0.01 \mathrm{~mA} / \mathrm{cm}^{2}$, which could alternatively be described as $3.96 \mathrm{~mA} / \mathrm{g}$ or a C/50 rate based on the theoretical capacity of $198 \mathrm{~mA} / \mathrm{g}$. 


\section{Results and Discussion}

A blue crystal with approximate dimensions of $0.2 \times 0.1 \times 0.1 \mathrm{~mm}^{3}$ whose compositions was eventually determined to be $\mathrm{Li}_{3} \mathrm{Mo}_{4} \mathrm{P}_{5} \mathrm{O}_{24}$ was used for the collection of single crystal X-ray diffraction data using Mo $K_{\alpha}$ radiation. The data were indexed to a monoclinic unit cell with refined lattice parameters of $a=14.5643(9) \AA, b=8.7528(5) \AA, c=14.6630(10) \AA$, and $\beta=108.738(7)^{\circ}$. After a careful investigation of reflection intensities, systematic absence of $l=$ odd for all $h 0 l$ reflections, and $k=$ odd for $0 k 0$ reflections were identified based on the integrated reflection intensities (and which were visually confirmed in reconstructed reciprocal lattice planes, as shown in Figure S2), a set of conditions which uniquely identifies the space group as $P 2_{1}$ (No. 14). Structure solution was carried out using direct methods with Sir2004 ${ }^{12}$, though it is noted that similar results were obtained when charge flipping using Superflip ${ }^{13}$ was carried out within Jana2006 $^{14}$. All non-Li atoms positions were first identified in this manner, and Li atom site positions were next found through the analysis of positive peaks in Fourier difference maps in the course of further refinements carried out using Shelxl software ${ }^{15}$. In this manner, it was found that the blue crystals have the composition of $\mathrm{Li}_{3} \mathrm{Mo}_{4} \mathrm{P}_{5} \mathrm{O}_{24}$ with $Z=4$.

Although this composition allowed all positive peaks in the Fourier density map to be identified, least-squares refinements using these atom positions still gave relatively large values of the refinement $R_{1}$ relative to the inherent noise in the data $\left(R_{\text {int }}\right)$, potentially indicating the presence of twinning. Further evidence for twining was found by inspecting the list of worst-fit reflections, which were observed to generally have much higher predicted than observed intensities. Using the PLATON software ${ }^{16}$, a twin matrix of $\left[\begin{array}{llllllll}0 & 0 & 1 & 0 & -1 & 0 & 1 & 0\end{array}\right]$ was identified and the minority twin 
domain was found to represent about $10 \%$ of the sample. The twin law corresponds to a two-fold axis rotation in the [101] real space direction, and coincidentally also about the (101) reciprocal space direction. It is expected that this twin law arises due to the very similar $a$ and $c$ lattice parameters of this compound, which differ by only $0.7 \%$. After incorporating twinning into the refinement, no further indications of problems were seen in the $R$ values and $\chi^{2}$ for the refinement, and no evidence for missing atomic sites was seen in Fourier difference maps. Details of the data collection procedure and structure refinement results are given in Table 1. The atomic parameters are given in Table S1, while important bond distances and angles together with a bond valence sum analysis are provided in Table S2.

Table 1. Data collection and refinement parameters $\mathrm{Li}_{3} \mathrm{Mo}_{4} \mathrm{P}_{5} \mathrm{O}_{24}$

\begin{tabular}{c|c}
\hline Temperature $(\mathrm{K})$ & 293 \\
Crystal size $\left(\mathrm{mm}^{3}\right)$ & $0.2 \times 0.1 \times 0.1$ \\
Wavelength $(\AA)$ & 0.71073 \\
Crystal system & monoclinic \\
Space group & $P 2_{1} / c$ \\
$a(\AA)$ & $14.5643(9)$ \\
$b(\AA)$ & $8.7528(5)$ \\
$c(\AA)$ & $14.6630(10)$ \\
$\beta\left({ }^{\circ}\right)$ & $108.738(7)$ \\
$\mathrm{V}\left(\AA^{3}\right)$ & $1770.14(19)$ \\
$\mathrm{Z}$ & 4 \\
Linear absorption & 3.35 \\
coefficient (mm $\left.{ }^{-1}\right)$ & $010-10100$ \\
Twin law & 3.34 to 33.04 \\
$\theta$ range $\left(^{\circ}\right)$ & -18 to 18 \\
$h$ & -10 to 10 \\
$k$ & -18 to 18 \\
$l$ & 23470 \\
$R_{\text {int }}$ & 3733 \\
Reflections collected & 327 \\
Unique reflections & 0.0545 \\
\hline
\end{tabular}




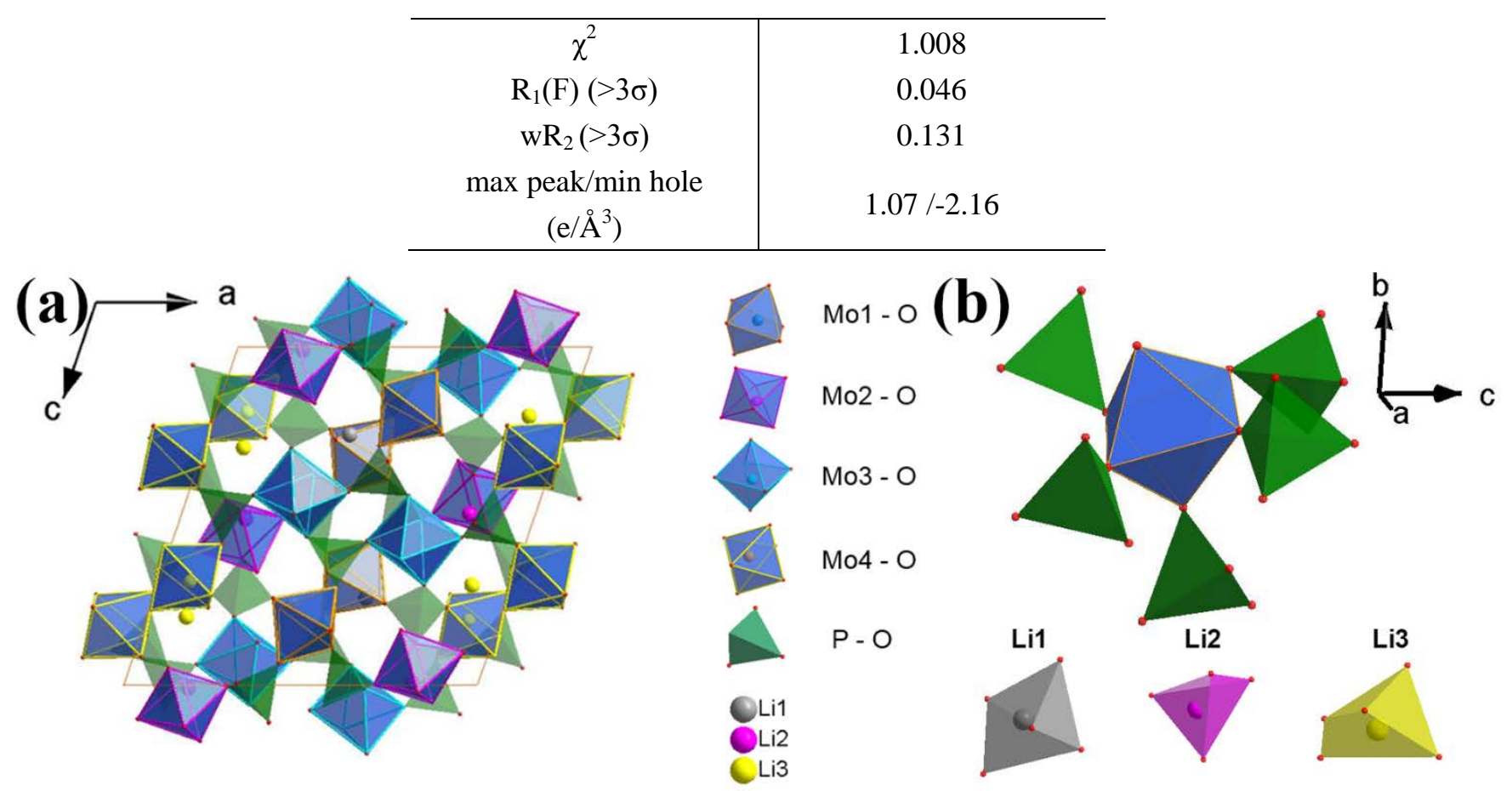

Figure 1. (a) Crystal structure of $\mathrm{Li}_{3} \mathrm{Mo}_{4} \mathrm{P}_{5} \mathrm{O}_{24}$. The four types of $\mathrm{MoO}_{6}$ octahedra are shown in blue with different edge colors, while $\mathrm{PO}_{4}$ tetrahedra are shown in green. (b) The 5 vertices of the $\mathrm{MoO}_{6}$ octahedra not associated with the $\mathrm{Mo}=\mathrm{O}$ double bond share a corner with a $\mathrm{PO}_{4}$ tetrahedron, as seen for MoO1. The 3 different types of $\mathrm{LiO}_{5}$ coordination polyhedra are also shown. 
(a)

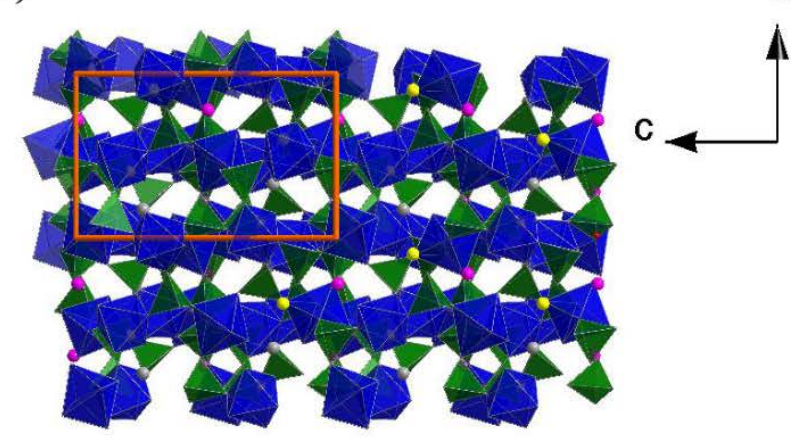

(c)

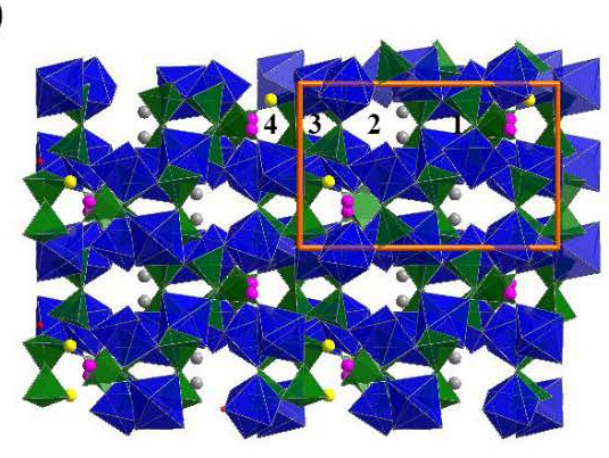

(b)

b (d)

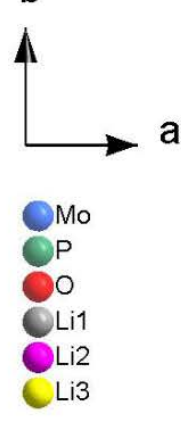

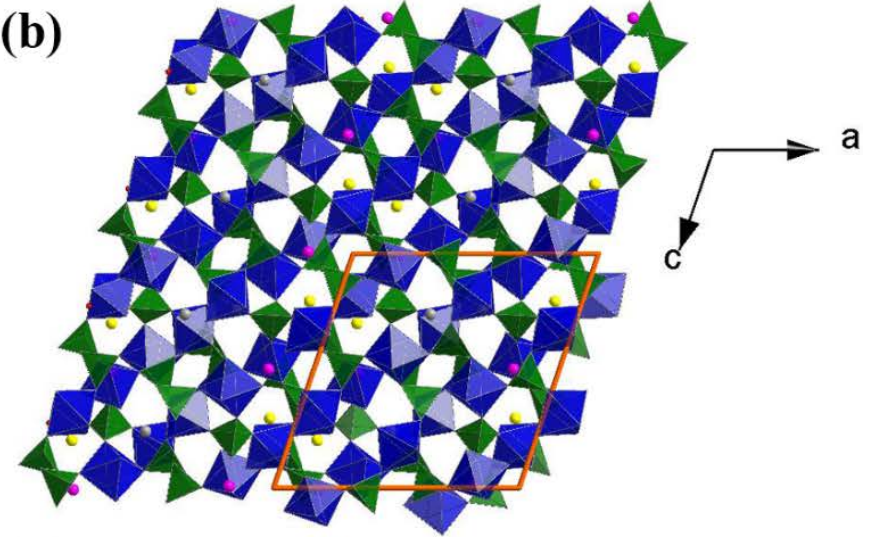

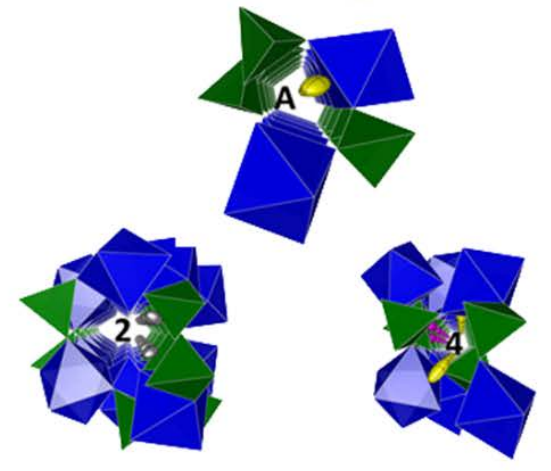

Figure 2. Structure of $\mathrm{Li}_{3} \mathrm{Mo}_{4} \mathrm{P}_{5} \mathrm{O}_{24}$ viewed along (a) the (100), (b) the (010) and (c) the (001) direction.

To better understand the multi-electron capabilities of Mo in this compound, it is important to have an in-depth understanding of its crystal structure, especially the bonding environment of Mo. The structure of $\mathrm{Li}_{3} \mathrm{Mo}_{4} \mathrm{P}_{5} \mathrm{O}_{24}$ is shown in Figure 1a. Within this structure, all atoms reside on general sites; with a total of 36 independent atomic sites that include 4 different $\mathrm{Mo}, 5 \mathrm{P}, 3 \mathrm{Li}$ and $24 \mathrm{O}$ atomic sites. Each $\mathrm{MoO}_{6}$ octahedron corner-shares oxygens with 5 neighboring $\mathrm{PO}_{4}$ tetrahedra (Figure $1 \mathrm{~b}$ ). The free $6^{\text {th }}$ oxygen vertex in the $\mathrm{MoO}_{6}$ octahedra is always associated with a very short Mo-O bond (1.64 $\AA$ to $1.65 \AA$ ) indicating the presence of a $\mathrm{Mo}=\mathrm{O}$ double bond at this position. A consequence of the $\mathrm{Mo}=\mathrm{O}$ double bond is that - the apical Mo-O single bond opposite to the double bond is always long (2.13 - 2.16 $\AA$ ) relative to the four equatorial Mo-O single bonds, which have more conventional bond lengths of $1.93 \AA$ to $2.07 \AA$. 
The P-O bond distances within the five types of $\mathrm{PO}_{4}$ groups in this compound range from $1.51 \AA$ to $1.56 \AA$, fully consistent with the many prior structural reports for compounds with isolated phosphate groups. Three different types of lithium sites are found in this structure, as shown in Figure 1b. Li1 occupies the center of a distorted triagonal bipyramid with Li-O bond distances ranging from $1.92 \AA$ to $2.16 \AA$. Li2 sits at the bottom of a distorted tetrahedron formed by four different oxygen atoms, while Li3 is at the center of a highly distorted square pyramid.

Bond valence sum (BVS) calculations (Table S2) confirm that the short Mo-O bonds are indeed characteristic of double bonds. The total Mo valence calculated using the BVS parameters of $r_{0}=1.85$ and $b=0.37$ suggested for $\mathrm{Mo}^{5+}$ are 5.09, 5.14, 5.05 and 4.97, for the Mo1, Mo2, Mo3 and Mo4 sites respectively. This confirms that each Mo site in this structure has the average valence of $5+$ suggested by the refined stoichiometry ${ }^{20}$, and that Mo charge disproportionation, as has been recently discovered for $\mathrm{La}_{2} \mathrm{MoO}_{5}$, does not occur in this compound ${ }^{21}$. The Li valences calculated for the Li1, Li2 and Li3 sites using parameters of $r_{0}=1.47$ and $b=0.37$ are $1.10,0.911$ and 0.900 respectively, indicating normal behavior for these sites $^{22}$.

Although the stoichiometry of $\mathrm{Li}_{3} \mathrm{Mo}_{4} \mathrm{P}_{5} \mathrm{O}_{24}$ (Space group $P 2_{1} /$ ) is analogous to that of the previously reported phases $\mathrm{K}_{3}(\mathrm{MoO})_{4}\left(\mathrm{PO}_{4}\right)_{5}(\mathrm{Pbca})$ and $\mathrm{Na}_{3}(\mathrm{MoO})_{4}\left(\mathrm{PO}_{4}\right)_{5}(\mathrm{C} 2 / \mathrm{C})^{23,24}$, each of these compounds crystallizes in a different space group with different connectivities between $\mathrm{MoO}_{6}$ octahedra and $\mathrm{PO}_{4}$ tetrahedra. This is presumably because of the large ionic radii difference among $\mathrm{Li}^{+}, \mathrm{Na}^{+}$and $\mathrm{K}^{+}$, which necessitate the formation of very different sizes of cavities for these monopositive ions within the covalently bonded framework of these compounds. It can be seen that wider openings in the framework occur for both $\mathrm{Na}_{3}(\mathrm{MoO})_{4}\left(\mathrm{PO}_{4}\right)_{5}$ (Figure S3) and $\mathrm{K}_{3}(\mathrm{MoO})_{4}\left(\mathrm{PO}_{4}\right)_{5}$ (Figure S4). This allows more than one 
cation site to be found in each channel, in contrast to the more compact framework of $\mathrm{Li}_{3} \mathrm{Mo}_{4} \mathrm{P}_{5} \mathrm{O}_{24}$ (Figure 2) in which the mobile ion channels are always narrower and do not span the diameter of multiple

\section{Li cations.}

The open space within the $\mathrm{Li}_{3} \mathrm{Mo}_{4} \mathrm{P}_{5} \mathrm{O}_{24}$ framework can be seen when the structure of this compound is viewed along the (100), (010) and (001) directions, as shown in Figure 2a-c. In each case, gaps in the structure appear as white space along multiple channels in the projection direction. Furthermore, it appears that the channels intersect each other and that the effective diffusion pathways may be two- or three-dimensional rather than one dimensional. This hypothesis, however, needs to be investigated by more robust techniques such as DFT or BVS difference maps before strong conclusions can be made in this regard ${ }^{25,26}$. A BVS difference map generated using a very small $|\Delta V|$ threshold of 0.05 valence unit clearly displays a three dimensional network of lithium-ion diffusion pathways (Figure 3), indicating that this framework is expected to have sufficient Li-ion mobility to serve as a battery cathode material. However, the BVS-calculated pathways do not take the form of rods running parallel to the primary crystallographic directions, indicating that the channels of white space seen in polyhedral representations of the structure are generally too small to permit facile ion motion. Interestingly, only the Li2 and Li3 sites are part of the 3D percolating pathways seen for the $|\Delta \mathrm{V}|=0.05$ map. The Li1 sites are isolated at this threshold, and do not become part of the percolating pathway until maps are generated with a significantly higher threshold of $|\Delta \mathrm{V}|=0.16$. As such, it is expected that it will be harder to remove Li-ions from the Li1 sites, a hypothesis which can be directly investigated in the future through structural studies of chemically or electrochemically delithiatied $\mathrm{Li}_{3} \mathrm{Mo}_{4} \mathrm{P}_{5} \mathrm{O}_{24}$. In addition to supporting $\mathrm{Li}$ removal, the open nature of this framework with regard to $\mathrm{Li}$ ions suggests that it may be possible to intercalate additional Li1 ions 
beyond the three originally present in this phase when this material is chemically or electrochemically subjected to reducing conditions suitable for driving lithiation reactions.
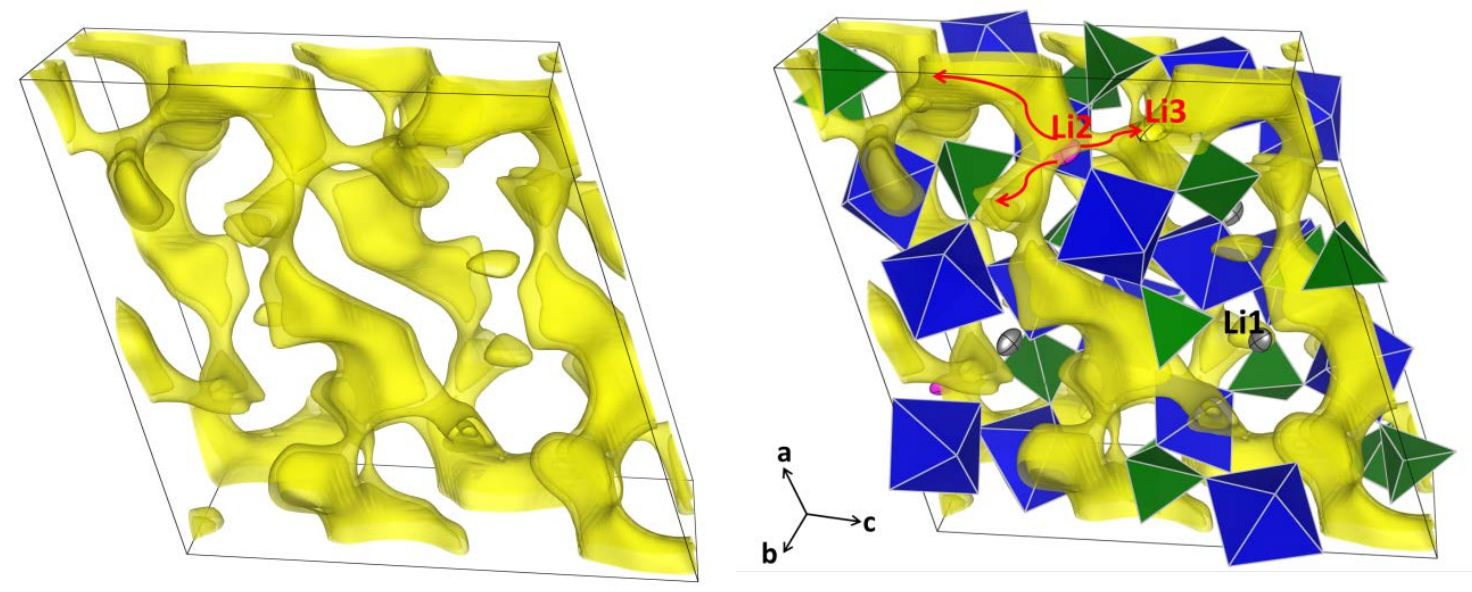

Figure 3. Bond valence sum difference map for $\mathrm{Li}_{3} \mathrm{Mo}_{4} \mathrm{P}_{5} \mathrm{O}_{24}$ with $|\Delta \mathrm{V}|=0.05$ valence units. The $\mathrm{Li} 2$ and Li3 sites are connected in a 3D percolating network, while the Li1 site remains isolated for $|\Delta \mathrm{V}|<0.16$ valence units. Potential diffusion paths connecting the Li2 and Li3 sites are indicated in red.

While the structure of one phase has been unambiguously determined from our single crystal diffraction study, it can be seen in powder diffraction studies that the synthesis reaction did not produce a single-phase product (Figure 4). A Rietveld refinement was carried out using high-resolution synchrotron $\mathrm{X}$-ray diffraction data collected on the 11-BM beamline of the APS. It can be seen that $\mathrm{Li}_{3} \mathrm{Mo}_{4} \mathrm{P}_{5} \mathrm{O}_{24}$ is the majority phase, and that most powder diffraction peaks in the pattern can be effectively fit using the structural model obtained from single crystal diffraction data without further refinement. $\mathrm{MoO}_{2}$ is present as an impurity phase at $20 \%$ of the weight fraction of $\mathrm{Li}_{3} \mathrm{Mo}_{4} \mathrm{P}_{5} \mathrm{O}_{24}$. There are clearly additional peaks which derive from (at least) one additional impurity phase, presumably corresponding to the dark gray crystals obtained from the melt. Based on a mass balance, the unindexed impurity phases must be Mo-deficient relative to the $\mathrm{Li}_{3} \mathrm{Mo}_{4} \mathrm{P}_{5} \mathrm{O}_{24}$ stoichiometry. 


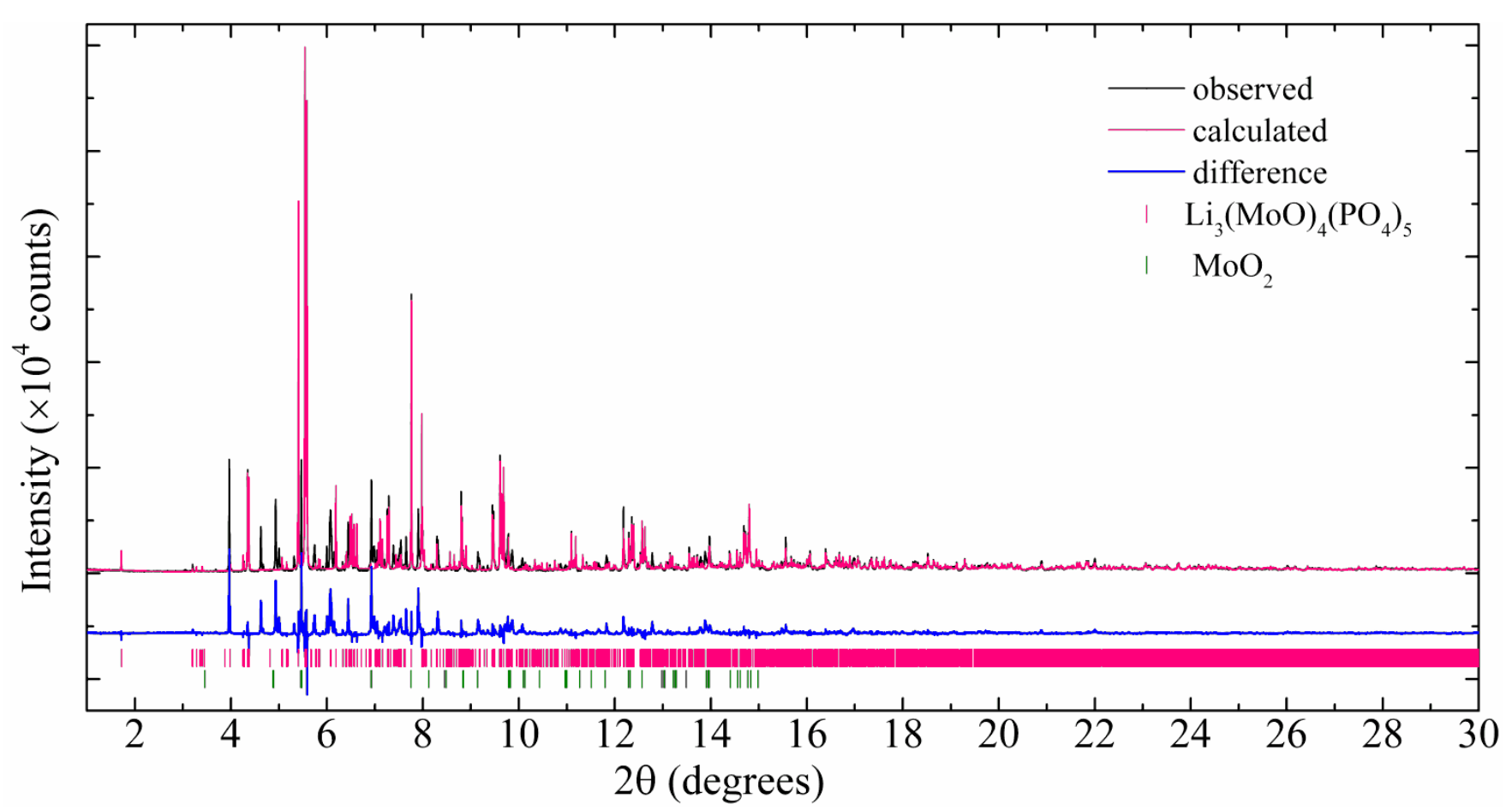

Figure 4. Synchrotron powder diffraction pattern $(\lambda=0.413670 \AA)$ of the as-synthesized melt product, reflection tick marks for $\mathrm{Li}_{3} \mathrm{Mo}_{4} \mathrm{P}_{5} \mathrm{O}_{24}$ are shown in red and those for $\mathrm{MoO}_{2}$ in green.

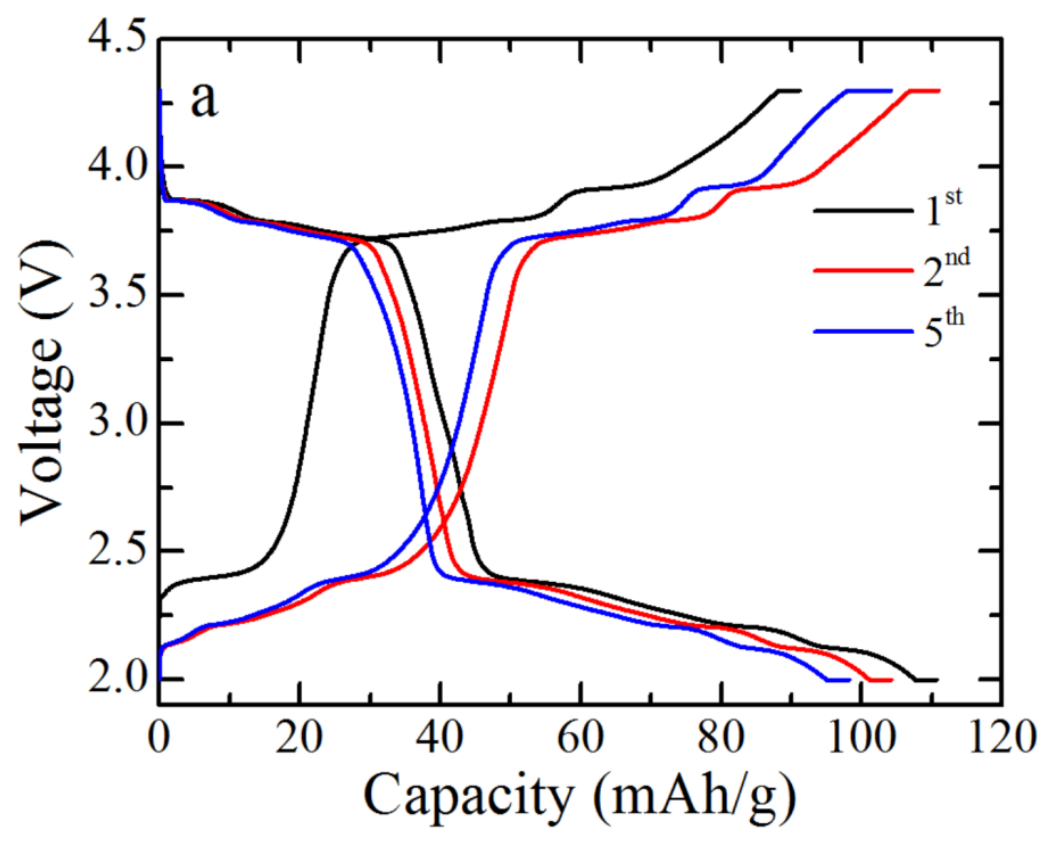



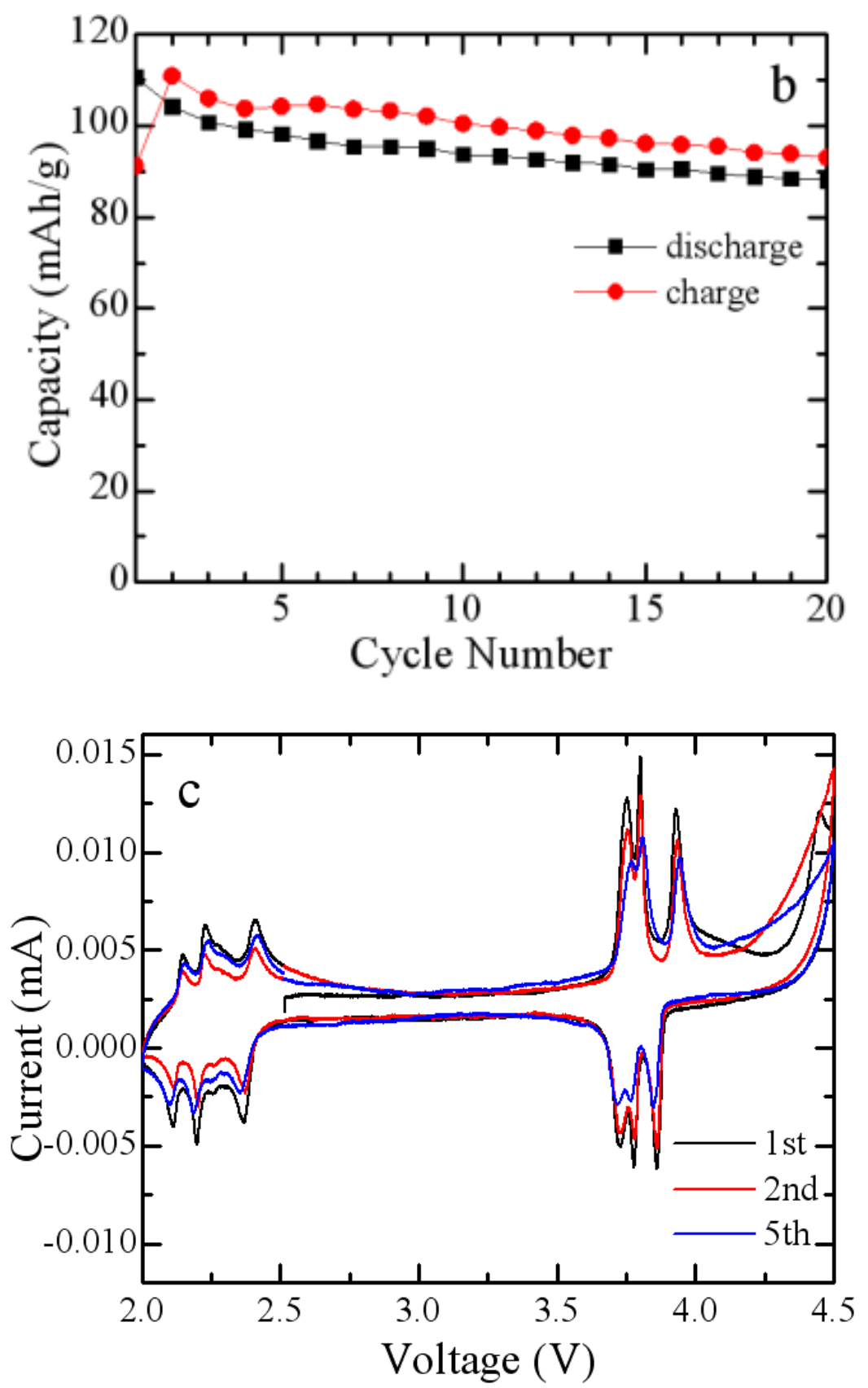

Figure 5. Electrochemical properties of $\mathrm{Li}_{3} \mathrm{Mo}_{4} \mathrm{P}_{5} \mathrm{O}_{24}$, including (a) galvanostatic charge-discharge curves of the $1^{\text {st }}, 2^{\text {nd }}$ and $5^{\text {th }}$ cycle at $\mathrm{C} / 50$, (b) capacity retention of $\mathrm{Li}_{3} \mathrm{Mo}_{4} \mathrm{P}_{5} \mathrm{O}_{24}$ over 20 cycles, and (c) cyclic voltammetry curves collected with a scan rate of $0.005 \mathrm{mV} / \mathrm{s}$.

The electrochemical performance of $\mathrm{Li}_{3} \mathrm{Mo}_{4} \mathrm{P}_{5} \mathrm{O}_{24}$ as cathode in a lithium-ion battery has been investigated. Due to the inhomogenous nature of the reaction product, it is known that the ceramic 
material used to prepare electrodes contained less than $80 \%$ of $\mathrm{Li}_{3} \mathrm{Mo}_{4} \mathrm{P}_{5} \mathrm{O}_{24}$, though the exact amount is unknown due to the presence of an unidentified impurity phase and reported specific capacities are not normalized to this approximate phase purity. The OCV of the cell is $\sim 2.5 \mathrm{~V}$ and testing started with a charge cycle to first remove the lithium from the structure while oxidizing $\mathrm{Mo}^{5+}$ to $\mathrm{Mo}^{6+}$. The subsequent discharge should then insert lithium to first drive the reduction of $\mathrm{Mo}^{6+}$ to $\mathrm{Mo}^{5+}$ and then $\mathrm{Mo}^{5+}$ to $\mathrm{Mo}^{4+}$ if multiple oxidation states of Mo are accessible. Since there are fewer Li sites than Mo cations in the structure, the theoretical capacity associated with the $\mathrm{Mo}^{6+} / \mathrm{Mo}^{5+}$ couple $(85 \mathrm{mAh} / \mathrm{g})$ is about $75 \%$ of that associated with the $\mathrm{Mo}^{5+} / \mathrm{Mo}^{4+}$ couple $(113 \mathrm{~mA} / \mathrm{g})$, and a total specific capacity of $198 \mathrm{mAh} / \mathrm{g}$ is expected (based on a starting composition of $\mathrm{Li}_{3} \mathrm{Mo}_{4} \mathrm{P}_{5} \mathrm{O}_{24}$ ) if both couples are fully accessible.

When cycled at a rate of $\mathrm{C} / 50, \mathrm{Li}_{3} \mathrm{Mo}_{4} \mathrm{P}_{5} \mathrm{O}_{24}$ exhibits two major reversible plateaus in the voltage range of $2.0-4.3 \mathrm{~V}$ vs. $\mathrm{Li}^{+} / \mathrm{Li}$, as seen in Figure 5a. The higher-voltage plateau is centered around $3.8 \mathrm{~V}$ (corresponding to the $\mathrm{Mo}^{6+} / \mathrm{Mo}^{5+}$ redox couple and composition of $\mathrm{Li}_{3-\mathrm{x}} \mathrm{Mo}_{4} \mathrm{P}_{5} \mathrm{O}_{24}$ ), while the low-voltage plateau is centered around $2.2 \mathrm{~V}$ (corresponding to the $\mathrm{Mo}^{5+} / \mathrm{Mo}^{4}+$ redox couple and the insertion of $\mathrm{Li}$ into $\mathrm{Li}_{3+\mathrm{y}} \mathrm{Mo}_{4} \mathrm{P}_{5} \mathrm{O}_{25}$ ). The $\sim 3.8 \mathrm{~V}$ process has a capacity of about $70 \mathrm{mAh} / \mathrm{g}$ on charge but only $40 \mathrm{mAh} / \mathrm{g}$ on discharge, while the situation is reversed for the $\sim 2.2 \mathrm{~V}$ process $(40 \mathrm{mAh} / \mathrm{g}$ on charge; $70 \mathrm{mAh} / \mathrm{g}$ on discharge). This large hysteresis is likely associated with the potential co-existence of the two redox couples, as the presence of any $\mathrm{Mo}^{4+}$ will pin the potential at $\sim 2.2 \mathrm{~V}$ during discharge, and vice-versa with $\mathrm{Mo}^{6+}$ on charging. Both the high and the low voltage plateaus show additional substructure, as is expected if the $\mathrm{Li}^{+}$ions preferentially enter and leave specific sites rather than randomly occupying the multiple sites whose occupancy changes across each redox couple ( 3 for the high-voltage plateaus, and 4 for the low-voltage plateaus if all Li sites have the same multiplicity). This is in fact fully consistent with the 
results of cyclic voltammetry studies of this phase (Figure 5c), in which 7 distinct peaks can be resolved across the two major plateaus. This result is important as it indicates that all four Mo sites are participating in redox processes, and that there is no intrinsic reason why the full $198 \mathrm{mAh} / \mathrm{g}$ specific capacity of this phase should not be accessible if the sample purity, electrode construction, and cell design are optimized in follow-up studies.

The compound $\mathrm{Li}_{3} \mathrm{Mo}_{4} \mathrm{P}_{5} \mathrm{O}_{24}$ can be reversibly cycled over tens of cycles, as is illustrated by the data of Figure 5. A comparison of the charge-discharge curves for different cycles shows that the plateaus maintain a similar shape after multiple cycles. The initial reversible capacity is $\sim 110 \mathrm{mAh} / \mathrm{g}$ over a voltage window of $2.0-4.3 \mathrm{~V}$ vs. $\mathrm{Li}^{+} / \mathrm{Li}$, with $\sim 80 \%$ of this capacity retained after 20 cycles. The CV data shows that current increases quickly at voltage above $4.3 \mathrm{~V}$, which is a likely signature of electrolyte decomposition. This suggests that this irreversible process may play a role in the capacity fade even when cycling over the narrower range of $2.0-4.3 \mathrm{~V} \mathrm{vs.} \mathrm{Li}^{+} / \mathrm{Li}$, as may also be inferred from the voltage profile of $\mathrm{Li}_{3} \mathrm{Mo}_{4} \mathrm{P}_{5} \mathrm{O}_{24}$ above $4 \mathrm{~V}$ during galvanostatic cycling studies. This upper voltage limit is relatively low with respect to other Li-ion battery systems, indicating that the capacity retention of this system may be substantially improved if alternative electrolytes are explored. Although the performance of $\mathrm{Li}_{3} \mathrm{Mo}_{4} \mathrm{P}_{5} \mathrm{O}_{24}$ has not yet been optimized, the present electrochemical data unambiguously indicate that the Mo cations in $\mathrm{Li}_{3} \mathrm{Mo}_{4} \mathrm{P}_{5} \mathrm{O}_{24}$ are able to reversibly access Mo oxidation states between 4+ and 6+ when this material is used as the cathode of a Li-ion battery. There appear to be no inherent limitations associated with accessing two different redox couples of Mo cations in the present framework rather than simply utilizing a single redox couple, as has been done for the vast majority of cathode materials investigated to date.

\section{Conclusions}


The structure of the novel compound $\mathrm{Li}_{3} \mathrm{Mo}_{4} \mathrm{P}_{5} \mathrm{O}_{24}$ has been solved through single crystal diffraction studies, and has been confirmed to be the predominant phase in the melts through powder diffraction investigations. The relatively open Mo-P-O framework of this compound is calculated to have many 3D diffusion pathways in BVS map, which can support the solid state diffusion of Li-ions. The electrochemical removal of $\mathrm{Li}^{+}$from this phase occurs around 3.8 $\mathrm{V}\left(\mathrm{Li}_{3-\mathrm{x}} \mathrm{Mo}_{4} \mathrm{P}_{5} \mathrm{O}_{24}\right)$, while $\mathrm{Li}^{+}$insertion can be driven at potentials around $2.2 \mathrm{~V}\left(\mathrm{Li}_{3+\mathrm{y}} \mathrm{Mo}_{4} \mathrm{P}_{5} \mathrm{O}_{24}\right)$, and both of these redox processes can be accessed in a reversible manner with only modest ( 20 \%) capacity fade over 20 cycles. There is substantial ( $\sim 30 \mathrm{mAh} / \mathrm{g}$ ) hysteresis in the voltage profile at the cross-over between the $\mathrm{Mo}^{6+} / \mathrm{Mo}^{5+}$ and the $\mathrm{Mo}^{5+} / \mathrm{Mo}^{4+}$ redox couples, a complication which may be an inherent aspect of the utilization of multiple redox couples. Although the specific capacity of $110 \mathrm{mAh} / \mathrm{g}$ achieved in the present sample was substantially less than the theoretical capacity of $198 \mathrm{mAh} / \mathrm{g}$, cyclic voltammetry data suggests that all 4 Mo sites can access the $\mathrm{Mo}^{5+} / \mathrm{Mo}^{4+}$ redox couple, and that there are no battier to all of these sites accessing the $\mathrm{Mo}^{5+} / \mathrm{Mo}^{4+}$ redox couple other than the limited amount of Li ions present in stoichiometric compound. It is therefore expected that a much higher fraction of the theoretical capacity will be accessible once the sample synthesis and device construction are further optimized. This compound clearly demonstrates the viability of the utilization of multiple redox states of Mo in rechargeable batteries, and illustrates the potential of polyanionic compounds with $\mathrm{MoO}_{6}$ octahedra to support low-battier Li-ion diffusion pathways. These results provide general insights into some of the mechanisms, possibilities, and limitations of reversibly utilizing multiple oxidation states of molybdenum for electrochemical energy storage.

Supporting Information. SEM images of pristine and ball-milled materials; reconstructed reciprocal 
lattice images of $\mathrm{Li}_{3} \mathrm{Mo}_{4} \mathrm{P}_{5} \mathrm{O}_{24}$; structure drawings of $\mathrm{Na}_{3}(\mathrm{MoO})_{4}\left(\mathrm{PO}_{4}\right)_{5}$ and $\mathrm{K}_{3}(\mathrm{MoO})_{4}\left(\mathrm{PO}_{4}\right)_{5}$; atomic positions and anisotropic displacement parameters of $\mathrm{Li}_{3} \mathrm{Mo}_{4} \mathrm{P}_{5} \mathrm{O}_{24}$; selected bond distance and BVS-calculated site valences of $\mathrm{Li}_{3} \mathrm{Mo}_{4} \mathrm{P}_{5} \mathrm{O}_{24}$.

\section{Acknowledgement}

Use of the Advanced Photon Source at Argonne National Laboratory was supported by the U. S.

Department of Energy, Office of Science, Office of Basic Energy Sciences, under Contract No.

DE-AC02-06CH11357. This work was supported as part of the NorthEast Center for Chemical Energy

Storage (NECCES), and Energy Frontier Research Center funded by the U.S. Department of Energy

Office of Science, Basic Energy Sciences under Award \# DE-SC0012583. Also acknowledge NSF CRIF

for SXRD support.

\section{References}

1. Whittingham, M. S. Lithium Batteries and Cathode Materials. Chem. Rev. 2004, 104, 4271-301.

2. Padhi, A. K.; Nanjundaswamy, K.; Goodenough, J. B. Phospho-olivines as Positive-Electrode Materials for Rechargeable Lithium Batteries. J. Electrochem Soc. 1997, 144, 1188-1194.

3. Whittingham, M. S. Ultimate Limits to Intercalation Reactions for Lithium Batteries. Chem. Rev. 2014, 114, 11414-11443.

4. Zhou, H.; Upreti, S.; Chernova, N. A.; Hautier, G.; Ceder, G.; Whittingham, M. S. Iron and Manganese Pyrophosphates as Cathodes for Lithium-Ion Batteries. Chem. Mater. 2011, 23, 293-300.

5. $\quad$ Nishimura, S.-i.; Nakamura, M.; Natsui, R.; Yamada. A. New Lithium Iron Pyrophosphate as 3.5 V Class Cathode Material for Lithium Ion Battery. J. Am. Chem. Soc. 2010, 132, 13596-13597.

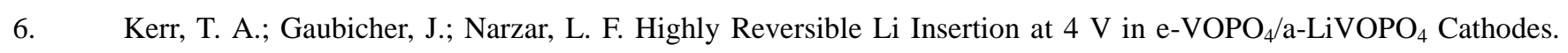
Electrochem. Solid-State Lett. 2000, 3, 460-462.

7. Bianchini, M.; Ateba-Mba, J. M.; Dagault, P.; Bogdan, E.; Carlier, D.; Suard, E.; Masquelier, C.; Croguennec, L. Multiple Phases in the $\varepsilon-\mathrm{VPO}_{4} \mathrm{O}-\mathrm{LiVPO}{ }_{4} \mathrm{O}-\mathrm{Li}_{2} \mathrm{VPO}_{4} \mathrm{O}$ System: a Combined Solid State Electrochemistry and Diffraction Structural Study. J. Mater. Chem. A. 2014, 2, 10182-10192.

8. $\quad$ Chen, Z.; Chen, Q.; Chen, L.; Zhang, R.; Zhou, H.; Chernova, N. A.; Whittingham, M. S. Electrochemical Behavior of Nanostructured $\varepsilon-\mathrm{VOPO}_{4}$ over Two Redox Plateaus. J. Electrochem Soc. 2013, 160, A1777-A1780.

9. Hautier, G.; Jain, A.; Ong, S. P.; Kang, B.; Moore, C.; Doe, R.; Ceder, G. Phosphates as Lithium-Ion Battery 
Cathodes: An Evaluation Based on High-Throughput ab Initio Calculations. Chem. Mater. 2011, 23, 3495-3508.

10. Wen, B.; Chernova, N. A.; Zhang, R.; Wang, Q.; Omenya, F.; Fang, J.; Whittingham, M. S. Layered Molybdenum (Oxy)Pyrophosphate as Cathode for Lithium-Ion Batteries. Chem. Mater. 2013, 25, 3513-3521.

11. Farrugia, L.J. WinGX and ORTEP for Windows: an Update. J. Appl. Crystallogr. 2012, 45, 849-854.

12. Burla, M. C.; Caliandro, R.; Camalli, M.; Carrozzini, B.; Cascarano, G. L.; Caro, L. D.; Giacovazzo, C.; Polidori, G.; Spagna. R. SIR2004: an Improved Tool for Crystal Structure Determination and Refinement. J. Appl. Crystallogr. 2005, 38, 381-388.

13. Palatinus, L.; Chapuis, G. SUPERFLIP - a Computer Program for the Solution of Crystal Structures by Charge Flipping in Arbitrary Dimensions. J. Appl. Crystallogr. 2007, 40, 786-790.

14. Petříček, V.; Dušek, M.; Palatinus, L. Crystallographic Computing System JANA2006: General Features. Zeitschrift für Kristallographie - Crystalline Materials 2014, 229, 345-352.

15. Sheldrick, G. M. A Short History of SHELX. Acta. Crystallogr. A, 2008, 64, 112-122.

16. Spek, A.L. Structure Validation in Chemical Crystallography. Acta. Crystallogr. D. 2009, 65, $148-155$.

17. Liu, J.; Chang, D. H.; Whitfield, P.; Janssen, Y.; Yu, X. Q.; Zhou, Y. N.; Bai, J. M.; Ko, J.; Nam, K. W.; Wu, L. J.; Zhu, Y. M.; Feygenson, M.; Amatucci, G.; Van der Ven, A.; Yang, X. Q.; Khalifah, P. Ionic Conduction in Cubic $\mathrm{NaTiP}_{3} \mathrm{O}_{9} \mathrm{~N}$, a Secondary Na-Ion Battery Cathode with Extremely Low Volume Change. Chem. Mater. 2014, 26, 3295-3305.

18. Momma, K.; Izumi, F. VESTA: a Three-Dimensional Visualization System for Electronic and Structural Analysis. J. Appl. Crystallogr. 2008, 41, 653-658.

19. $\quad$ Lee, P. L.; Shu, D.; Ramanathan, M.; Preissner, C.; Wang, J.; Beno, M. A.; Von Dreele, R. B.; Ribaud, L.; Kurtz, C.; Antao, S. M.; Jiao, X.; Toby, B. H. A Twelve-Analyzer Detector System for High-Resolution Powder Diffraction. J. Synchrotron Rad. 2008, 15, 427-432.

20. Chen, M.; Zhou, Z.; Hu, S. Bond Valence Parameters Linearly Dependent on the Molybdenum Oxidation States. Chinese Sci. Bull., 2002, 47, 978-981.

21. Colabello, D. M.; Camino, F. E.; Huq, A.; Hybertsen, M.; Khalifah, P. G. Charge Disproportionation in Tetragonal $\mathrm{La}_{2} \mathrm{MoO}_{5}$, a Small Band Gap Semiconductor Influenced by Direct Mo-Mo Bonding. J. Am. Chem. Soc. 2015, 137, 3, 1245-1257.

22. Brown, I. D. The Bond-Valence Method: An Empirical Approach to Chemical Structure and Bonding. Structure and Bonding in Crystals. 1981, 2, 1-30.

23. Hoareau, T.; Leclaire, A.; Borel, M. M.; Grandin, A.; Raveau, B. A Mo Monophosphate with a Tunnel Structure: $\mathrm{K}_{3}(\mathrm{MoO})_{4}\left(\mathrm{PO}_{4}\right)_{5}$. J. Solid State Chem. 1995, 114, 61-65.

24. Leclaire, A.; Hoareau, T.; Borel, M. M.; Grandin, A.; Raveau, B. A Sodium Mo Monophosphate with a Tunnel Structure: $\mathrm{Na}_{3}(\mathrm{MoO})_{4}\left(\mathrm{PO}_{4}\right)_{5}$. J. Solid State Chem. 1995, 114, 543-549.

25. Dathar, G. K. P.; Sheppard, D.; Stevenson, K. J.; Henkelman, G. Calculations of Li-Ion Diffusion in Olivine Phosphates. Chem. Mater. 2011, 23, 4032-4037.

26. Schindlera, M.; Hawthornec, F. C.; Alexandera, M. A.; Kutluoglua, R. A.; Mandalievb, P.; Haldenc, N. M.; Mitchella, R. H. Na-Li- $\left[\mathrm{V}_{3} \mathrm{O}_{8}\right]$ insertion electrodes: Structures and diffusion pathways. J. Solid State Chem. 2006, 179, 2616-2628. 
TOC Graphic

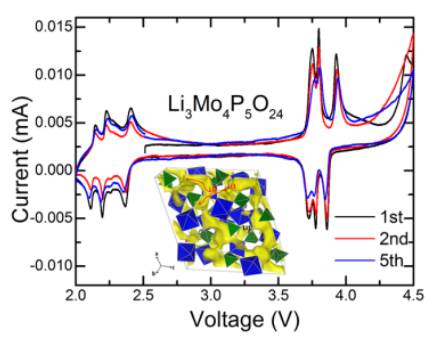




\section{Supporting Information}

\section{$\mathrm{Li}_{3} \mathrm{Mo}_{4} \mathrm{P}_{5} \mathrm{O}_{24}$ : a Two-Electron Cathode for Lithium-Ion Batteries with Three-Dimensional}

\section{Diffusion Pathways}

Bohua Wen, Jue Liu, Natasha A. Chernova, Xiaoya Wang, Yuri Janssen, Fredrick Omenya, Peter G. Khalifah, and M. Stanley. Whittingham

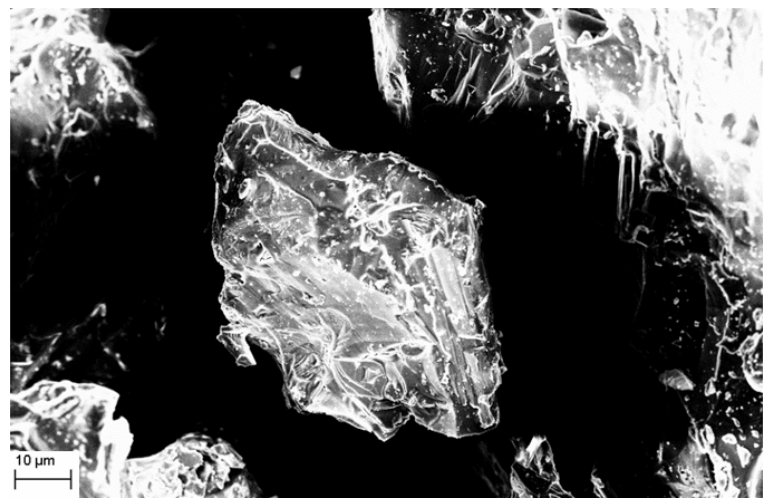

(a)

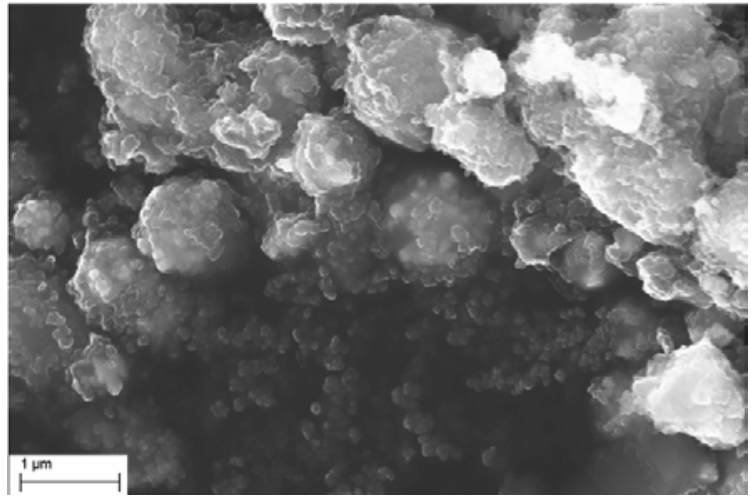

(b)

Figure S1. SEM images of synthesis product (a) before and (b) after ball milling. 

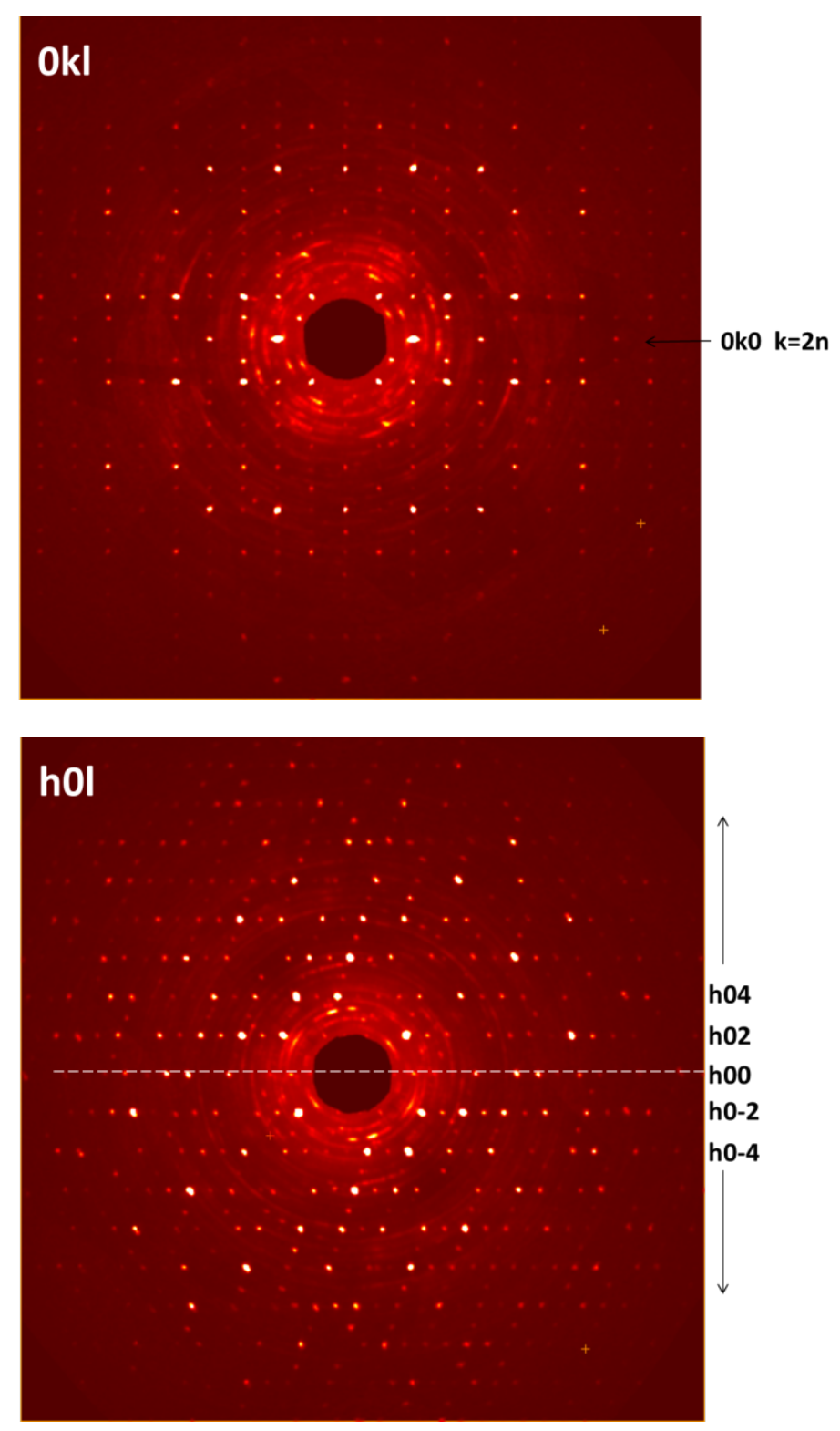

Figure S2. Reconstructed reciprocal lattice images for $\mathrm{Li}_{3} \mathrm{Mo}_{4} \mathrm{P}_{5} \mathrm{O}_{24}$ in $0 k l$ and $h 0 l$ planes. 


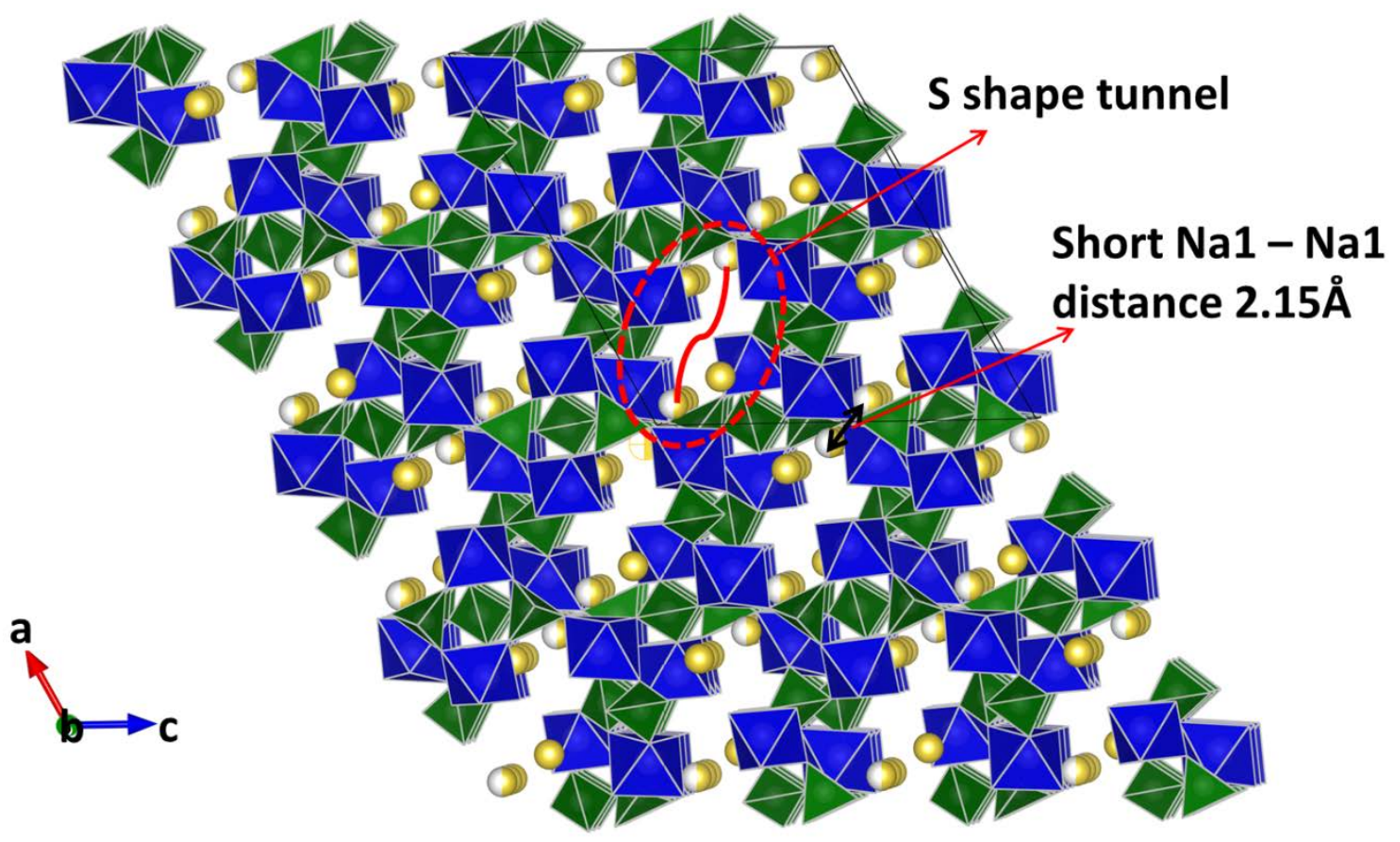

Figure S3. Structure of $\mathrm{Na}_{3}(\mathrm{MoO})_{4}\left(\mathrm{PO}_{4}\right)_{5}$ viewed along the (010) direction. $\mathrm{MoO}_{6}$ octahedra are shown in blue and $\mathrm{PO}_{4}$ tetrahedra in green.

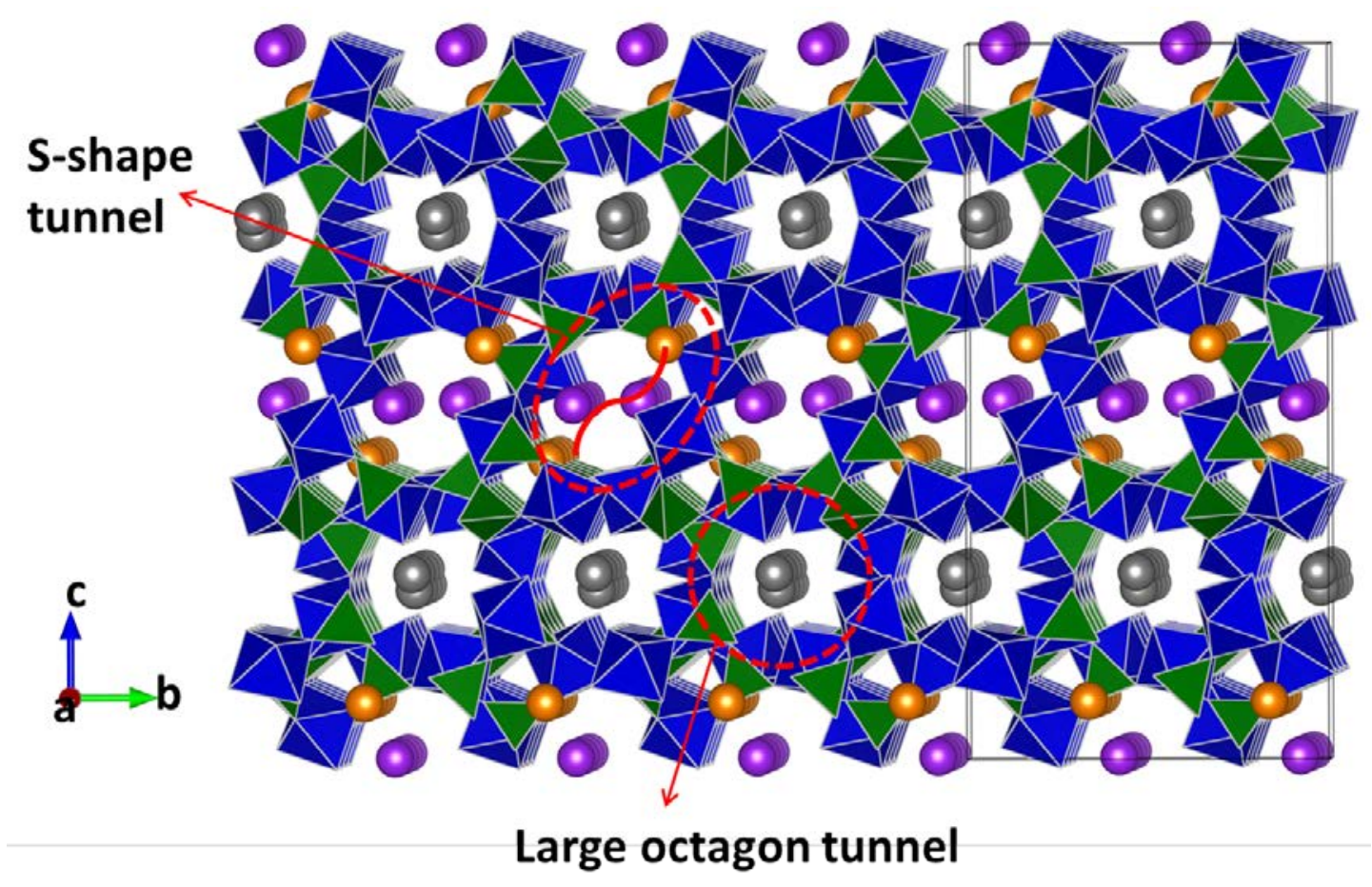

Figure S4. Structure of $\mathrm{K}_{3}(\mathrm{MoO})_{4}\left(\mathrm{PO}_{4}\right)_{5}$ viewed along the (100) direction. $\mathrm{MoO}_{6}$ octahedra are shown in blue and $\mathrm{PO}_{4}$ tetrahedra in green. 
Table S1. Atomic positions and anisotropic displacement parameters $\left(\AA^{2}\right)$ of $\mathrm{Li}_{3} \mathrm{Mo}_{4} \mathrm{P}_{5} \mathrm{O}_{24}$.

\begin{tabular}{|c|c|c|c|c|c|c|c|c|c|}
\hline Atom & $x$ & $y$ & $Z$ & $U_{\text {eq }}\left(\AA^{2}\right)$ & $U_{22}\left(\AA^{2}\right)$ & $U_{33}\left(\AA^{2}\right)$ & $U_{12}\left(\AA^{2}\right)$ & $U_{13}\left(\AA^{2}\right)$ & $U_{23}\left(\AA^{2}\right)$ \\
\hline Li1 & $0.3685(2)$ & $0.3887(3)$ & $0.5101(2)$ & $0.0100(7)$ & $0.0063(12)$ & $0.0124(13)$ & $-0.0018(10)$ & $0.0085(10)$ & $0.0001(10)$ \\
\hline Li2 & $0.24394(19)$ & $0.2367(3)$ & $0.2244(2)$ & $0.0107(7)$ & $0.0053(12)$ & $0.0135(13)$ & $-0.0005(10)$ & $0.0059(10)$ & $-0.0001(10)$ \\
\hline Li3 & $0.4764(2)$ & $0.6077(3)$ & $0.12680(19)$ & $0.0096(7)$ & $0.0041(12)$ & $0.0132(13)$ & $-0.0009(10)$ & $0.0084(10)$ & $-0.0011(10)$ \\
\hline Mo1 & $0.44193(6)$ & $0.46996(10)$ & $0.31634(6)$ & $0.0102(3)$ & $0.0054(4)$ & $0.0141(5)$ & $0.0003(4)$ & $0.0083(3)$ & $-0.0002(3)$ \\
\hline Mo2 & $0.19363(6)$ & $0.55355(11)$ & $0.56491(7)$ & $0.0104(3)$ & $0.0051(4)$ & $0.0144(5)$ & $-0.0002(4)$ & $0.0078(3)$ & $0.0008(3)$ \\
\hline Mo3 & $0.32395(7)$ & $0.01364(11)$ & $0.42683(6)$ & $0.0102(2)$ & $0.0056(4)$ & $0.0131(4)$ & $0.0011(3)$ & $0.0081(3)$ & $0.0003(3)$ \\
\hline Mo4 & $0.08798(7)$ & $0.53362(10)$ & $0.19260(6)$ & $0.0111(3)$ & $0.0069(5)$ & $0.0140(4)$ & $0.0010(4)$ & $0.0083(3)$ & $0.0011(3)$ \\
\hline P1 & $0.1246(2)$ & $0.8957(3)$ & $0.4793(2)$ & $0.0102(8)$ & $0.0056(13)$ & $0.0134(13)$ & $0.0001(10)$ & $0.0078(10)$ & $-0.0007(10)$ \\
\hline $\mathbf{P 2}$ & $-0.0145(2)$ & $0.6203(3)$ & $0.6297(2)$ & $0.0104(8)$ & $0.0052(12)$ & $0.0137(14)$ & $-0.0010(10)$ & $0.0080(10)$ & $0.0003(10)$ \\
\hline P3 & $0.3637(5)$ & $0.6108(9)$ & $0.2714(6)$ & $0.019(3)$ & $0.014(4)$ & $0.031(5)$ & $0.003(4)$ & $0.010(3)$ & $0.004(3)$ \\
\hline P4 & $0.4171(6)$ & $0.4203(9)$ & $0.4343(6)$ & $0.017(2)$ & $0.012(4)$ & $0.020(4)$ & $-0.002(3)$ & $0.015(3)$ & $-0.004(3)$ \\
\hline P5 & & 0.3977 & & & & $0.014(4)$ & $0.001(3)$ & $0.008(3)$ & $8(3)$ \\
\hline 01 & $0.3402(6)$ & $0.3153(9)$ & $0.2428(6)$ & $0.018(2)$ & $0.014(4)$ & $0.019(4)$ & $-0.005(3)$ & $0.007(3)$ & $-0.006(3)$ \\
\hline $\mathrm{O} 2$ & $0.5065(5)$ & $0.4898(9)$ & $0.2097(5)$ & $0.013(2)$ & $0.008(4)$ & $0.019(4)$ & $0.002(3)$ & $0.011(3)$ & $0.002(3)$ \\
\hline O3 & $0.5318(5)$ & $0.2696(8)$ & $0.3367(5)$ & $0.011(2)$ & $0.005(4)$ & $0.019(4)$ & $0.002(3)$ & $0.012(3)$ & $0.001(3)$ \\
\hline 04 & $0.2692(6)$ & $0.6272(10)$ & $0.6641(6)$ & $0.020(3)$ & $0.014(4)$ & $0.020(4)$ & $0.001(3)$ & $0.009(4)$ & $-0.004(4)$ \\
\hline O5 & $0.1616(6)$ & $0.7340(9)$ & $0.4789(6)$ & $0.019(3)$ & $0.008(4)$ & $0.020(4)$ & $-0.001(3)$ & $0.015(4)$ & $0.003(3)$ \\
\hline O6 & $0.2934(5)$ & $0.5139(9)$ & $0.5025(5)$ & $0.014(2)$ & $0.005(4)$ & $0.026(4)$ & $-0.004(3)$ & $0.014(3)$ & $-0.002(3)$ \\
\hline O7 & $0.44193(6)$ & $0.46996(10$ & $0.31634(6)$ & $0.018(2)$ & $0.012(4)$ & $0.022(4)$ & $0.005(3)$ & $0.014(3)$ & $0.005(3)$ \\
\hline O8 & $0.19363(6)$ & $0.55355(11)$ & $0.56491(7)$ & $0.014(2)$ & $0.006(4)$ & $0.017(4)$ & $0.003(3)$ & $0.011(3)$ & $0.002(3)$ \\
\hline O9 & $0.32395(7)$ & $0.01364(11)$ & $0.42683(6)$ & $0.016(2)$ & $0.011(4)$ & $0.016(4)$ & $-0.001(3)$ & $0.010(3)$ & $0.001(3)$ \\
\hline 010 & $0.0719(6)$ & $0.5784(9)$ & $0.5992(6)$ & $0.021(2)$ & $0.010(4)$ & $0.028(4)$ & $-0.001(3)$ & $0.013(4)$ & $0.004(3)$ \\
\hline 011 & $0.2122(5)$ & $0.1665(9)$ & $0.1233(5)$ & $0.016(2)$ & $0.013(4)$ & $0.020(4)$ & $-0.004(3)$ & $0.008(3)$ & $-0.004(3)$ \\
\hline 012 & $0.1099(6)$ & $0.4117(9)$ & $0.4474(5)$ & $0.013(2)$ & $0.006(4)$ & $0.018(4)$ & $0.002(3)$ & $0.011(3)$ & $-0.001(3)$ \\
\hline 013 & $0.3364(6)$ & $-0.1482(9)$ & $0.3726(6)$ & $0.016(2)$ & $0.009(4)$ & $0.019(4)$ & $0.002(3)$ & $0.010(3)$ & $-0.003(3)$ \\
\hline 014 & $0.3756(5)$ & $0.5613(9)$ & $0.0597(5)$ & $0.0134(19)$ & $0.005(3)$ & $0.027(4)$ & $0.005(3)$ & $0.010(3)$ & $0.003(3)$ \\
\hline 015 & $0.5503(5)$ & $0.6018(8)$ & $0.0731(5)$ & $0.014(2)$ & $0.005(4)$ & $0.023(4)$ & $-0.005(3)$ & $0.011(3)$ & $-0.001(3)$ \\
\hline 016 & $0.2472(5)$ & $0.1117(9)$ & $0.2979(6)$ & $0.025(3)$ & $0.026(5)$ & $0.026(5)$ & $-0.006(4)$ & $0.009(4)$ & $-0.007(4)$ \\
\hline 017 & $0.1867(5)$ & $1.0045(9)$ & $0.4381(5)$ & $0.020(2)$ & $0.018(4)$ & $0.022(4)$ & $0.007(3)$ & $0.009(3)$ & $0.010(3)$ \\
\hline
\end{tabular}




\begin{tabular}{|l|c|c|c|c|c|c|c|c|c|}
\hline $\mathbf{O 1 8}$ & $0.3174(5)$ & $0.2338(9)$ & $0.4918(6)$ & $0.021(3)$ & $0.025(5)$ & $0.018(4)$ & $-0.001(4)$ & $0.010(3)$ & $0.002(4)$ \\
\hline O19 & $0.1642(6)$ & $0.6511(10)$ & $0.2680(6)$ & $0.017(2)$ & $0.010(4)$ & $0.027(4)$ & $0.004(3)$ & $0.015(3)$ & $0.004(3)$ \\
\hline O20 & $0.1613(6)$ & $0.3404(10)$ & $0.2313(6)$ & $0.014(2)$ & $0.003(4)$ & $0.022(4)$ & $-0.001(3)$ & $0.009(3)$ & $0.000(3)$ \\
\hline O21 & $0.1416(6)$ & $0.9508(10)$ & $0.5826(5)$ & $0.016(2)$ & $0.006(4)$ & $0.025(4)$ & $0.002(3)$ & $0.012(3)$ & $0.002(3)$ \\
\hline O22 & $-0.0043(5)$ & $0.5272(8)$ & $0.7224(5)$ & $0.022(6)$ & $0.018(10)$ & $0.025(10)$ & $0.009(9)$ & $0.013(8)$ & $0.005(8)$ \\
\hline O23 & $-0.0161(5)$ & $0.7934(8)$ & $0.6497(5)$ & $0.026(7)$ & $0.012(10)$ & $0.048(13)$ & $-0.007(10)$ & $0.020(10)$ & $0.003(8)$ \\
\hline O24 & $0.0210(5)$ & $0.9102(9)$ & $0.4146(6)$ & $0.042(9)$ & $0.064(19)$ & $0.042(14)$ & $-0.030(13)$ & $0.012(10)$ & $-0.018(12)$ \\
\hline
\end{tabular}


Table S2. Selected bond distance and BVS-calculated site valences

\begin{tabular}{|l|l|l|l|l|l|}
\hline Bond types & Distance $(\AA)$ & Bond types & Distance $(\AA)$ & Atoms & BVS \\
\hline Mo1-O1 & $1.6646(78)$ & Li2-O11 & $1.9066(251)$ & Mo1 & 5.09 \\
\hline Mo1-O2 & $1.9265(74)$ & Li2-O18 & $1.9901(218)$ & Mo2 & 5.14 \\
\hline Mo1-O3 & $2.0074(76)$ & Li2-O12 & $2.0641(228)$ & Mo3 & 5.05 \\
\hline Mo1-O4 & $2.0403(78)$ & Li2-O17 & $2.1301(239)$ & Mo4 & 4.97 \\
\hline Mo1-O5 & $2.0737(67)$ & Li3-O16 & $1.9605(237)$ & P1 & 5.07 \\
\hline Mo1-O6 & $2.1510(71)$ & Li3-O22 & $2.0244(239)$ & P2 & 5.12 \\
\hline Mo2-O7 & $1.6472(80)$ & Li3-O23 & $2.0484(257)$ & P3 & 4.99 \\
\hline Mo2-O8 & $1.9805(81)$ & Li3-O17 & $2.1650(299)$ & P4 & 5.08 \\
\hline Mo2-O9 & $1.9812(68)$ & Li3-O20 & $2.5237(315)$ & P5 & 5.09 \\
\hline Mo2-O10 & $2.0048(76)$ & P1-O2 & $1.5234(76)$ & Li1 & 1.14 \\
\hline Mo2-O11 & $2.0894(76)$ & P1-O9 & $1.5261(75)$ & Li2 & 0.91 \\
\hline Mo2-O12 & $2.1562(78)$ & P1-O18 & $1.5283(77)$ & Li3 & 0.90 \\
\hline Mo3-O13 & $1.6625(79)$ & P1-O3 & $1.5373(81)$ & & \\
\hline Mo3-O14 & $1.9615(77)$ & P2-O4 & $1.5067(80)$ & & \\
\hline Mo3-O15 & $1.9864(75)$ & P2-O16 & $1.5252(79)$ & & \\
\hline Mo3-O16 & $2.0507(78)$ & P2-O11 & $1.5330(79)$ & & \\
\hline Mo3-O17 & $2.0602(66)$ & P2-O20 & $1.5364(79)$ & & \\
\hline Mo3-O18 & $2.1652(74)$ & P3-O15 & $1.5257(73)$ & & \\
\hline Mo4-O19 & $1.6499(84)$ & P3-O6 & $1.5331(74)$ & & \\
\hline Mo4-O20 & $1.9832(80)$ & P3-O14 & $1.5362(78)$ & & \\
\hline Mo4-O21 & $2.0093(75)$ & P3-O5 & $1.5469(76)$ & & \\
\hline Mo4-O22 & $2.0731(71)$ & P4-O24 & $1.5077(79)$ & & \\
\hline Mo4-O23 & $2.0910(75)$ & P4-O8 & $1.5158(81)$ & & \\
\hline Mo4-O24 & $2.1336(76)$ & P4-O21 & $1.5324(80)$ & & \\
\hline Li1-O5 & $1.9223(214)$ & P4-O17 & $1.5618(74)$ & & \\
\hline Li1-O7 & $1.9894(227)$ & P5-O12 & $1.5090(83)$ & & \\
\hline Li1-O1 & $1.9981(223)$ & P5-O10 & $1.5098(78)$ & & \\
\hline Li1-O6 & $2.0275(207)$ & P5-O23 & $1.5447(77)$ & & \\
\hline Li1-O13 & $2.1622(214)$ & P5-O22 & $1.5496(78)$ & & \\
\hline
\end{tabular}

